\title{
Düşük Doz Nitrofurantoin ile Postkoital Antimikrobiyal Profilaksinin Premenapozal Gebe Olmayan Kadınlarda Komplike Olmayan Rekurren Uriner Trakt Enfeksiyonlarının Önlenmesinde Etkinliği
}

The Effectiveness of Postcoital Antimicrobial Prophylaxis Low Dose Nitrofurantoin in Uncomplicated Recurrent Urinary Tract İnfections Among Non-Pregnant Premenopausal Women

\author{
Kemal SANDAL ${ }^{1}$, Murat YASSA ${ }^{1}$, Arzu Bilge TEKİN ${ }^{1}$, Mehmet Akif SARGIN ${ }^{1}$, Niyazi TUĞ ${ }^{1}$ \\ 1. Sağlık Bilimleri Üniversitesi, Sancaktepe Şehit Prof. Dr. İlhan Varank Eğitim ve Araștırma Hastanesi, Kadın Hastalıkları ve \\ Doğum Kliniği, İstanbul
}

\section{$\ddot{O Z E T}$}

Amaç: Rekürren üriner trakt enfeksiyonları (RUTE) yönetilmesi güç önemli bir halk sağllğl sorunudur. En sik etkeni Escherichia coli'dir. RUTE'nin önlenmesinde kontinü ve post-koital profilaksi seçenekleri arasından post-koital profilaksi daha az doz gerektirmesi ve benzer etkinlik ile öne çımaktadır. Bu çalışmada post-koital profilaksinin RUTE'nin önlenmesindeki etkinliğinin araştırılması amaçlanmışıır.

Gereçler ve Yöntem: Bu retrospektif çalışmaya RUTE sebebiyle düşük doz nitrofurantoin ile post-koital profilaksi ve yaşam tarzl değişiklikleri uygulanan premenapozal, gebe olmayan, cinsel aktif kadınlar dahil edilmistir. Profilaksi altı ayda sonlandırılmış ve sonraki altı aylık takipleri değerlendirilmiştir.

Bulgular: Çalışmaya toplam 39 hasta dahil edilmiştir. 1 hasta hafif gastrointestinal yan etki üzerine ilacı bırakmıștır. Tanımlaylcr istatistik analizine 38 hasta dahil edilmistir. Profilaksi süresince hiçbir hastada rekürrens görülmemiş olup başart oranı \%100'dür. Profilaksi sonrast altı aylık dönemde ise 1 hastada (\%2.63) 4.ayda rekürrens görülmüş̧ür. Profilaksi başlangıcından itibaren 12 aylık başarı \%97.37 (n=37/38) olarak bulunmuştur

Sonuç: Düşük doz (50 mg) nitrofurantoin ile post-koital profilaksisi; premenapoz, gebe olmayan rekürren üriner trakt enfeksiyonlu kadınlarda profilaksi süresince ve profilaksi sonrasi ilk altı ayda etkili ve güvenli bulunmuştur. Bu etkinin doğrulanmast için longitudinal prospektif çalışmalara ihtiyaç vardır.

Anahtar Kelimeler: nitrofurontain, rekürren üriner trakt enfeksiyonları, postkoital profilaksi

\section{ABSTRACT}

Objective: Recurrent urinary tract infection (RUTI) is an important public health problem in terms of disease management Most frequently the agent is Escherichia coli. Protection methods include continous and post-coital prophylaxis, latter has similar efficiency with lesser drug dosage. In this study we aimed to investigate the efficiency of post-coital prophylaxis in prevention of RUTI.

Material and Methods: We retrospectively evaluated premenopausal, non-pregnant, and sexually active adult women whom were suggested to use single dose of $50 \mathrm{mg}$ of nitrofurantion per oral in terms of post-coital prophylaxis for six months along with lifestyle modifications. Data of follow up examination after six months of therapy were also included.

\section{İletişim:}

Sorumlu Yazar: Kemal SANDAL

Adres: Merdivenköy Mah. Ressam Salih Erimez Cad. No:15/8 Kadıköy, İstanbul, Türkiye

Tel: +90 (553) 6294545

E-Posta: kemalsandal@gmail.com

Makale Geliş: 19.07.2018

Makale Kabul: 26.07.2018

DOI: http://dx.doi.org/10.16948/zktipb.445759
Results: Thirty nine patients were included. One patient couldn't complete the prophylaxis due to gastrointestinal side effects. Data of thirty eight patients were statistically evaluated. There wasn't any recurrence of RUTI and success rate was $100 \%$. In terms of follow up examinations, one patient had a recurrent four months after the end of prophylaxis. Overall success rate for twelve months was $97.4 \%$.

Conclusion: Post-coital prophylaxis with low dose nitrofurantion was found both effective and safe for treatment of premenopausal, non-pregnant women with RUTI for both six months of treatment and six months of follow up period. This effect should be further evaluated with longitudinal prospective studies.

Keywords: recurrent urogenital tract infection, nitrofurontain, post coital prophylaxis

\section{GíRiş}

Kadınların en az üçte birinin 24 yaşına kadar bir veya daha komplike olmayan üriner trakt enfeksiyonu geçirmekte olduğu ve \%60'ının yașam boyu en az bir kez geçireceği bildirilmiştir (1). Pik insidans cinsel aktif 18-39 yaşlardır ve kadınların \%30-40'1nda bir veya daha fazla rekürrens görülmektedir.

Rekürren üriner trakt enfeksiyonu (RUTE) bir önceki üriner trakt enfeksiyonunun komplet rezolüsyonunun ardından görülen semptomatik enfeksiyondur ve son 6 ayda iki veya dafa fazla veya son bir yılda 3 veya daha fazla görülen komplike olmayan kültür ile doğrulanmış üriner trakt enfeksiyonu olarak tanımlanmaktadır (2).

RUTE Morbiditesi düşük olmasına rağmen yaşam kalitesini negatif yönde etkilemektedir. Düzenli aralıklarla görülen sistit epizodlarının kadınlarda üriner mesane kanseri riskini yaklaşık 2.7 kat arttırdığ 1 görülmüştür (3). 5 epizoda kadar RUTE atakları antibiyotik ile tedavi edildiğinde bu riskin genç kadınlarda \%35 azaldığı görülmüştür.

RUTE için bağımsız risk faktörleri son bir ayda geçirilmiş cinsel aktivite, son bir yılda spermisid kullanımı, son bir yılda yeni partner, ilk üriner trakt enfeksiyonunu 15 yaşından önce geçirmiş olmak ve anne öyküsü olarak belirlenmiştir (4).

Önleme stratejileri içinde yaşam tarzı değişiklikleri, antibiyotik bazlı ve non-antibiyotik yöntemler gelmektedir. 
Antibiyotik bazlı yöntemler arasında kontinü antibiyotik profilaksisi (KAP), post-koital profilaksi (PP) ve hasta tarafindan başlanan antibiyoterapi yöntemi olarak üçe ayrılmaktadır. Non-antibiyotik yöntemler arasında östrojen tabletler, yabanmersini/kızılcık (cranberries) tabletleri, vitamin $\mathrm{C}$ ve metenamin tuzları, D-mannoz, laktobasil probiyotikleri, ve aşı başta gelmektedir (5). Non-antibiyotik önleme stratejilerinin başarılarına rağmen routine girmeleri için yeterli kanıt halen toplanamamıştır. Bireyselleştirilmiş antibiyotik profilaksisi halen RUTE'nin yönetimi ve önlenmesinde en etkili metod olmaya devam etmektedir (5).

Bu çalışmada düşük doz post-koital profilaksinin RUTE önlenmesindeki etkinliğinin değerlendirilmesi amaçlanmıştır.

\section{GEREÇ ve YÖNTEM}

$\mathrm{Bu}$ retrospektif çalışmaya 2016-2018 yıllar1 arasında tersiyer merkeze son altı ayda iki veya daha fazla komplike olmayan rekürren üriner trakt enfeksiyonu (RUTE) sebebiyle başvuran premenapoz ve cinsel aktif kadın hasta dahil edilmiştir.

Genitoüriner sistemden geçirilmiş operasyon öyküsü, bilinen genitoüriner malignite öyküsü, konjenital genitoüriner anomali, üriner inkontinans, anormal ürojinekolojik ultrasonografi bulgusu, bilinen nitrofurantoin duyarlılığ postmenapoz hastalar çalışmaya dahil edilmemiştir. RUTE son 6 ayda iki veya daha fazla veya son bir yılda 3 veya daha fazla idrar kültürü ile doğrulanmış, semptomatik, komplike olmayan üriner trakt enfeksiyon epizodları şeklinde tanımlanmıştır. Hastaların üriner trakt enfeksiyonları idrar kültürü ile doğrulanmış, hastalara uygun antibiyoterapi sonrası idrar kültürün negatifliği görüldükten sonra yaşam tarzı değişiklikleri eğitimi verilmiştir. Deri alerjenlerden, sıkı giysilerden, köpük banyolarından, spermisidlerden ve vajinal duştan uzak durma, bol sıv1 alımı ve sık idrara çıkma, cinsel aktivite öncesi ve sonrası işeme ve genital temizlik, arkadan-öne yerine önden-arkaya temizlik önerileri ve eğitimleri yapılmıştır (6).

Hastalara her cinsel aktivite sonrası ilk iki saat içerisinde bol suyla birlikte $50 \mathrm{mg}$ Nitrofurantoin başlanmıştır. Altı ay boyunca RUTE atağ 1 geçirmeyen hastalarda post-koital profilaksi durudurulmuş ve takibe alınmıştır. Profilaksi süresince ve profilaksi başlangıcından itibaren 12 aylık başarı oran (\%) şeklinde verilmiştir. Başarı rekürrens olmaması şeklinde tanımlanmıştır. Hastaların demografik verileri ve sonuçlarının istatistiksel analizinde Microsoft Excel programı kullanılmış ve değerler ortalama \pm standard sapma (SS), medyan, IQR (Inter-quartile range) ve oran (\%) olarak verilmiştir.

\section{BULGULAR}

Çalışmaya profilaksi başlanan toplam 39 hasta dahil edilmiştir. 1 hastada hafif bulantı ve ishal şeklinde antibiyotiğe bağlı olduğunu düşündüren gastrointestinal yan etki gelişmesi üzerine 1 hasta çalışma dışı bırakılmıştır. Yan etki oranı \%2.56 (n: 1/39) olarak bulunmuştur.

İstatistiksel analize dahil edilen toplam 38 hastanın yaş, parite, vücut-kitle indeksi (VKİ), ve son altı aydaki enfeksiyon sayıları Tablo 1'de gösterilmiştir.

Hastaların 2'sinde (\%5.26) rahim-içi araç mevcuttu. $\mathrm{Bu}$ hastalarda Rahim-içi araç enfeksiyon kaynağ 1 olarak görülmediğinden yerinde bırakılmıştır.

Post-koital profilaksi süresince (başlangıçtan itibaren ilk altı ay) hiçbir hastada RUTE gelişmemiş olup başarı oranı \%100 olarak bulunmuştur.

1 hastada (\%2.63) profilaksi sonrası altı ay içinde (profilaksi başlangıcından itibaren 10.ay) rekürrens görülmüştür. Profilaksi başlangıcından itibaren 12 aylık başarı \%97.37 $(n=37 / 38)$ olarak bulunmuştur.

\section{TARTIŞMA}

$\mathrm{Bu}$ retrospektif çalışmada RUTE tarifleyen cinsel aktif ve premenapozal kadınlara uygulanan düşük doz (50 mg) nitrofurantoin ile post-koital profilaksinin etkinliğinin profilaksi süresince (\%100) ve profilaksi sonrası ilk altı ay boyunca (\%97.37) yüksek olduğu görülmüsstür. Profilaksi süresince sadece 1 hastada (\%2.56) hafif yan etki görülmesi ile düşük doz nitrofurantoin ile post-koital profilaksinin güvenilir olabileceği gösterilmiştir.

Seksüel aktivitenin sıklığına bağlı olarak, post-koital profilaksinin kontinü profilaksiye üstünlüğü kullanılan dozun üçte bir veya daha azına inmesi ve dolayısıyla yan etkilerin minimalize edilmesidir $(7,8)$. Komplike olmayan RUTE profilaksisinde post-koital profilaksi Kanada Ürojinekoloji Birliği tarafından Kanıt düzeyi A olarak önerilmiştir (9).

RUTE'lerin önemli bir kısmı vajinal introitusu ve alt üriner traktın rektal kaynaklı olarak re-enfeksiyonu veya rekolonizasyonu ile meydana gelir (10). Cochrane analizine göre kadınlarda kontinü veya post-koital profilaksi sonrası ilk altı ayda 1.2-1.3/y1 RUTE atağ1 görülmektedir (11). Bu çalışmada görülen yüksek başarının sebebi hastalara verilen yoğun yaşam tarzı değişiklikleri eğitimi olabilir. Hijyen (önden-arkaya) ve diğerleri gibi basit ama etkili eğitim ve öneriler ile re-enfeksiyonun, post-koital profilaksi ile de rekolonizasyon azalmış olabileceği

Tablo 1: Demografik veriler.

\begin{tabular}{|l|c|c|c|c|c|}
\hline & Yaş (yıl) & Parite (n) & VKİ $\left(\mathrm{kg} / \mathrm{m}^{2}\right)$ & PP öncesi atak sayısı (n) & Cinsel aktivite sıklı̆̆ (n/ay) \\
\hline Min-Maks & $23-43$ & $0-4$ & $20.9-30.9$ & $2-6$ & $2-11$ \\
\hline Ortalama \pm SS & $32.25 \pm 6.9$ & n/a & $25.57 \pm 3.24$ & n/a & n/a \\
\hline Medyan, IQR & n/a & 1,3 & n/a & 3,2 & $5,2.75$ \\
\hline
\end{tabular}

VKİ: Vücut-Kitle İndeksi, PP: Post-koital profilaksi, IQR: Inter-quartile range 
kanaatindeyiz. $\mathrm{Bu}$, sonuçlarda bias oluşturabilir gibi gözükse de, yaşam tarzı değişikliklerinin klinik uygulamalarda anbitiyoterapi ile her zaman kombine edilmesi gerektiğini ve bu sebeple gerçekte biasın oluşmadığını düşünmekteyiz.

Nitrofurantoin düşük antibiyotik direnci, düșük maliyet, güvenli profili ve bölgeye spesifik olması sebebiyle tercih sebebidir (12). Nitrofurantoinin etki mekanızması tam olarak aydınlatılamamış olmasına rağmen, nitrofurantoinin RUTE tedavisindeki rolünün idrarı sterilize etme ve bakteriyel yapışmayı inhibe etmesi olduğu düşünülmektedir (13). Nitrofurantoin yalnızca üriner traktta terapötik aktif konsantrasyonlara ulaşması ve dolayısıyla aerobik intestinal dahil normal florayı etkilememesi sebebiyle idealdir (14). 40 farklı merkezi içeren 1142 E. coli içeren geniş serili antibiyotik direnç çalışmasında ampisiline direnç \%37.7, sülfametoksazol / trimethoprim \%21.3, siprofloksasin'e \%5.5, levofloksasine $\% 5.1$ ve nitrofurantoine direnç ise $\% 1.1$ olarak en düşük olarak bulunmuştur (15).

Price ve ark.larının 1063 hastanın dahil edildiği güncel sistematik gözden geçirme ve meta-analizinde nitrofurantoin, norfloksasin, trimethoprim, sülfametoksazol/trimethoprim, metamin hipürat, estriol veya sefaklor arasında klinik veya mikrobiyolojik kür açısından istatistiksel olarak anlamlı fark bulunmamıștır (RR,1.06; 95\% CI, 0.89-1.27; I2, 65\% ve RR, 1.06 ; $95 \%$ CI, 0.90-1.26; I2, 76\%, sirasiyla) (12). Nitrofurantoin'e bağlı yan etkinin diğer ajanlardan daha fazla olduğu saptanmasına rağmen bu yan etkilerin s1klikla gastrointestinal hafif yan etkilere bağlı ilacı bırakma şeklinde olduğu görülmüştür.

Calışmanın retrospektif olması, 1 yılın üzerinde takip olmaması çalıșmanın sınırlayıcı faktörleri arasinda sayılabilir. Gelecekte uzun dönemi kapsayan longitudinal prospektif çalışmaların dizayn edilmesi bu bulguların doğrulanması için gereklidir. Ek olarak, post-koital profilaksi uygulanan kadınların cinsel fonksiyonlarındaki değişikliklerin gösterilmesi, farklı antibiyotik ajanları arasında ve premanpoz / postmenapoz kadınlar arasında randomize kontrollü çalıșmaların düzenlenmesi literature olumlu katkı sağlayacaktır.

Yabanmersini / kızılcık (cranberries) sularının RUTE yönetiminde etkili olduğu bilgisine kar\$̧1 çıkan güncel veriler ortaya çıkmıştır. İki güncel randomize ve placebo kontrollü çalışmada plasebo ile 225 gram yabanmersini suyu karşılaştırıldı ğında anlamlı fark bulunamamıştır $(16,17)$. Bu veriler 1şı ğında antibiyoterapi ve tercihen post-koital profilaksi halen ilk seçenek olarak devam etmektedir. Son yıllarda E. coli O-antijeni umut vaadeden aşı hedefi olmuştur. 4 farklı E. coli serotiplerinin (ExPEC4V) O-antijenlerini içeren biyokonjugat aşının immünogenisitesi ve güvenilirliği faz $1 \mathrm{~b}$ çalışmasında gösterilmiştir (18). Tetravalan aşının tüm serotiplerine karşı fonksiyonel antikor cevabı ortaya çıkardığ 1 ve iyi tolere edildiği görülmüştür ve faz 2 çalışmalarına başlanmıştır.

\section{SONUÇLAR}

Düşük doz (50 mg) nitrofurantoin ile post-koital profilaksisi; premenapoz, gebe olmayan rekürren üriner trakt enfeksiyonlu kadınlarda profilaksi süresince ve profilaksi sonrası ilk altı ayda etkili ve güvenli bulunmuştur. Bu etkinin doğrulanması için longitudinal prospektif çalışmalara ihtiyaç vardır.

\section{KAYNAKLAR}

1. Hooton TM, Besser R, Foxman B, Fritsche TR, Nicolle LE. Acute uncomplicated cystitis in an era of increasing antibiotic resistance: a proposed approach to empirical therapy. Clinical Infectious Diseases. 2004;39(1):75-80

2. Nosseir SB, Lind LR, Winkler HA. Recurrent uncomplicated urinary tract infections in women: a review. Journal of women's health. $2012 ; 21(3): 347-54$

3. Vermeulen $S H$, Hanum $N$, Grotenhuis AJ, Castano-Vinyals G, Van Der Heijden $A G$, Aben $K K$, et al. Recurrent urinary tract infection and risk of bladder cancer in the Nijmegen bladder cancer study. British journal of cancer. 2015;112(3):594.

4. Scholes D, Hooton TM, Roberts PL, Stapleton AE, Gupta K, Stamm WE. Risk factors for recurrent urinary tract infection in young women. The Journal of infectious diseases. 2000;182(4):1177-82.

5. Aydin A, Ahmed K, Zaman I, Khan MS, Dasgupta P. Recurrent urinary tract infections in women. International urogynecology journal. 2015;26(6):795-804.

6. Al-Badr A, Al-Shaikh G. Recurrent urinary tract infections management in women: a review. Sultan Qaboos University Medical Journal. 2013;13(3):359

7. Nicolle LE. Prophylaxis: recurrent urinary tract infection in women. Infection. 1992;20(3):S203-S5.

8. Pfau A, Sacks T. Effective postcoital prophylaxis of recurrent urinary tract infections in premenopausal women: a review. International Urogynecology Journal. 1991;2(3):156-60.

9. Dason S, Dason JT, Kapoor A. Guidelines for the diagnosis and management of recurrent urinary tract infection in women. Canadian Urological Association Journal. 2011;5(5):316.

10. Hooton TM. Recurrent urinary tract infection in women. International journal of antimicrobial agents. 2001;17(4):259-68

11. Albert X, Huertas I, Pereiró I, Sanfelix J, Gosalbes V, Perrota $C$. Antibiotics for preventing recurrent urinary tract infection in non-pregnant women. The Cochrane database of systematic reviews. 2004(3):CD001209-CD

12. Price JR, Guran LA, Gregory WT, McDonagh MS. Nitrofurantoin vs other prophylactic agents in reducing recurrent urinary tract infections in adult women: a systematic review and meta-analysis. American journal of obstetrics and gynecology. 2016;215(5):548-60.

13. Zhanel GG, Nicolle LE. Effect of subinhibitory antimicrobial concentrations (sub-MICs) on in-vitro bacterial adherence to uroepithelial cells. Journal of Antimicrobial Chemotherapy. 1992;29(6):617-27.

14. Mavromanolakis E, Maraki S, Samonis G, Tselentis Y, Cranidis A Effect of norfloxacin, trimethoprim-sulfamethoxazole and nitrofurantoin on fecal flora of women with recurrent urinary tract infections. Journal of chemotherapy. 1997;9(3):203-7.

15. Zhanel GG, Hisanaga TL, Laing NM, DeCorby MR, Nichol KA, Weshnoweski B, et al. Antibiotic resistance in Escherichia coli outpatient urinary isolates: final results from the North American Urinary Tract Infection Collaborative Alliance (NAUTICA). International journal of antimicrobial agents. 2006;27(6):468-75.

16. Barbosa-Cesnik C, Brown MB, Buxton M, Zhang L, DeBusscher $J$, Foxman B. Cranberry juice fails to prevent recurrent urinary tract infection: results from a randomized placebo-controlled trial. Clinical infectious diseases. 2011;52(1):23-30.

17. Stapleton AE, Dziura J, Hooton TM, Cox ME, Yarova-Yarovaya Y, Chen $S$, et al., editors. Recurrent urinary tract infection and urinary Escherichia coli in women ingesting cranberry juice daily: a randomized controlled trial. Mayo Clinic Proceedings; 2012: Elsevier.

18. Huttner A, Hatz C, van den Dobbelsteen G, Abbanat D, Hornacek A, Frölich R, et al. Safety, immunogenicity, and preliminary clinical efficacy of a vaccine against extraintestinal pathogenic Escherichia coli in women with a history of recurrent urinary tract infection: a randomised, single-blind, placebo-controlled phase $1 \mathrm{~b}$ trial. The Lancet infectious diseases. 2017:17(5):528-37. 